\title{
INTENCIÓN Y RETÓRICA EN EL ZELUS CHRISTI CONTRA IUDAEOS, SARRACENOS ET INFIDELES DE PEDRO DE LA CAVALLERÍA (1450)*
}

\author{
POR \\ NúRIA GÓMEZ LLAUGER ${ }^{1}$ \\ Universitat Abat Oliba CEU
}

\section{RESUMEN}

El objetivo de este artículo es analizar las líneas básicas que definen la intención y el desarrollo retórico del tratado Zelus Christi contra ludaeos, Sarracenos et infideles, de Pedro de la Cavallería, escrito durante la segunda mitad del siglo XV en un contexto marcado de forma determinante por la Disputa de Tortosa (1413-1414).

PALABRAS CLAVE: Pedro de la Cavallería; Zelus Christi contra ludaeos, Sarracenos et infideles; Martín Alfonso Vivaldo; Sagradas Escrituras; Disputa de Tortosa; paulinismo; predicación.

\section{INTENTION AND RHETORIC IN THE ZELUS CHRISTI CONTRA IUDAEOS, SARRACENOS ET INFIDELES BY PEDRO DE LA CAVALLERÍA (1450)}

\author{
ABSTRACT \\ Disputation of Tortosa; paulinism; preaching. \\ Recibido/Received 04-09-2018 \\ Aceptado/Accepted 27-03-2020
}

The aim of this article is to analyze basic lines that define the intention and rhetorical development of the treatise Zelus Christi contra ludaeos, Sarracenos et infideles, by Pedro de la Cavallería, probably written during the second half of the 15th century in a clearly marked context by the Dispute of Tortosa (1413-1414).

KEY WORDS: Pedro de la Cavallería; Zelus Christi contra ludaeos, Sarracenos et infideles; Martín Alfonso Vivaldo; Holy Scriptures;

Cómo CITAR ESTE ARTículo / CITATION: Gómez Llauger, Núria. 2020. «Intención y retórica en el Zelus Christi contra ludaeos, Sarracenos et Infideles de Pedro de la Cavallería (1450)». Hispania Sacra LXXII, 146: 339-350. https://doi.org/10.3989/hs.2020.023

El tratado intitulado Zelus Christi contra ludaeos, Sarracenos et infideles (en adelante, Zelus Christi), escrito por el converso zaragozano Pedro de la Cavallería a mediados del siglo XV es, a mi modo de ver, una obra clave para el estudio de la apologética cristiana y la literatura de controversia que se produce durante este periodo en la Península Ibérica y, particularmente, en la Corona de Aragón. ${ }^{2}$

Después de las duras persecuciones de 1391, que en Castilla fueron claramente virulentas pero que al reino de Aragón llegaron ya un tanto atenuadas, ${ }^{3}$ los decenios

Este artículo se ha realizado en el marco de los Proyectos de investigación PGC2018-093472-B-C31 del Ministerio de Ciencia, Innovación y Universidades y 2007 SGR 1787 de la AGAUR (Generalitat de Catalunya).

1 ngomezl@uao.es /

ORCID iD: https://orcid.org/0000-0001-6329-5131

2 Hasta la fecha he publicado algunos artículos sobre este tratado: Ferrero Hernánez y Gómez Llauger 2013 y Gómez Llauger 2014.

3 Motis Dolader 2013, 15. siguientes estuvieron marcados de forma determinante por la campaña de predicación de Vicente Ferrer, que «insistía en que la desaparición del judaísmo debía producirse mediante el uso de la persuasión, y nunca con el recurso a la violencia física». ${ }^{4}$ Esta nueva forma de persecución no violenta ${ }^{5}$ se sustentaba, principalmente, en acciones de tipo legal ${ }^{6} y$

4 Cantera Montenegro 2002, 229.

5 Es preciso señalar, sin embargo, que a pesar de la preferencia de Vicente Ferrer por convertir a los judíos mediante la palabra, «con sus predicaciones provocaba en las masas una hostilidad manifiesta contra los judíos». Blasco Martínez 1997, 277.

6 Estas acciones se concretaron en disposiciones emanadas de las reuniones de Cortes. "Estas disposiciones tienen su punto álgido en el Ordenamiento de Valladolid de 1405 y, principalmente, en las leyes de Ayllón de 1412, inspiradas por San Vicente Ferrer, y cuyo objetivo consistía en dificultar al máximo la vida de los judíos para propiciar su más rápida conversión al cristianismo o, en su defecto, su marcha del reino. A este fin, se decretaba el apartamiento de los judíos en barrios aislados; el uso obligatorio de las señales distintivas sobre sus vestidos; 
en otras de tipo doctrinal, ${ }^{7}$ concretadas en las predicaciones en sinagogas promovidas por el mismo Vicente Ferrer, pero también en la famosa Disputa de Tortosa $(1413-1414)^{8}$ y las obras de polémica elaboradas por autores judeoconversos, ${ }^{9}$ entre las cuales destaca, sin duda, el Zelus Christi. Además, hay que tener en cuenta que, a partir de 1391, a los esfuerzos misioneros por convertir a los judíos que todavía permanecían en su religión original, se añadió la necesidad, más urgente si cabe, de catequizar a los ya convertidos o bautizados. ${ }^{10}$ Esto determinará también el paradigma de muchas de las obras de polémica antijudía que se escribirán tomando este contexto como marco de referencia.

Teniendo en cuenta estas consideraciones, en este artículo me propongo, en primer lugar, presentar someramente la estructura y el contenido del Zelus Christi para, a continuación, analizar tanto el patrón narrativo que lo articula como el uso que su autor y el editor que lo publicó posteriormente hacen de las fuentes doctrinales que el tratado maneja, con una atención especial a dos de ellas: las fuentes proféticas y las cartas paulinas. Una aportación final es la traducción del prólogo del tratado - que se ofrece en el apéndice-, puesto que su lectura completa es importante porque en él se encuentran varias claves interpretativas del texto. Con todo ello, mi intención es apuntar $-y$ fundamentar - algunas intuiciones respecto de la función de la obra tomando en consideración dos coordenadas principales: tanto su estructura y elementos internos como el contexto histórico-cultural en el que se gestó.

\section{EL ZELUS CHRISTI: TRATADO ORIGINAL Y EDICIÓN GLOSADA}

A pesar de haber sido escrito a mediados del siglo XV, el Zelus Christi no vio la luz hasta $1592 .{ }^{11}$ Su editor y glosador fue Martín Alfonso Vivaldo (1545-1605), un dominico nacido en Toledo - aunque el origen de su familia se encuentra en Génova- que ejerció como profesor de teología en Savona. ${ }^{12}$ Su actividad, pues, se desarrolló principalmente en Italia, y fue allí donde decidió editar el tratado. Esta edición ofrece numerosas glosas, amplias y prolijas en muchos casos, que no solo cumplen la función de comentarios addicionales al texto, sino que a menudo resultan fundamentales para la comprensión e interpretación del tratado.

la prohibición de ejercer diversos oficios; y otras medidas que suponían, de hecho, una limitación en la capacidad de autogobierno de las aljamas, como la necesidad de autorización por parte del monarca de los tributos internos. Incorporadas estas disposiciones a una bula, Benedicto XIII las declaró de obediencia general en toda la Cristiandad; asimismo, el rey Fernando I aprobó unas disposiciones similares para Aragón en el año 1415». Cantera Montenegro 2002, 231.

7 Ibídem, 231.

8 «Desde el punto de vista práctico, proselitista, la cuestión se jugaba en conseguir que los judíos se convencieran de que la conversión al cristianismo es el acto cabal del judaísmo verdadero, su corolario, que el cristianismo es el verdadero judaísmo, el judaísmo cumplido. La predicación de Vicente Ferrer y la política eclesiástica del Papa Benedicto XIII confluyen en esta dirección. El problema judío se resolvería sin violencia, "por la fuerza de la palabra y no de la espada" ". Sánchez Tortosa 2015, 161.

9 Cantera Montenegro 2002, 229-230.

10 Riera i Sans 1987, 114.

11 Vivaldus 1592.

12 «Italus. Dominicus Regularis Congregationis S. Salvatoris, Theologiae et Jurium Doctor 1590" Ad reverendi patris Claudii La Croix Societatis lesu, 61.
Fue a partir de ahí, gracias a la edición de Vivaldo, que el Zelus Christi circuló y tuvo una amplia difusión en diversas bibliotecas europeas. ${ }^{13}$ Sabemos, sin embargo, que la obra se conoció y se difundió en el ambiente cultural de la Corona de Aragón desde el momento mismo de su redacción, a mediados del siglo XV, o poco después, como lo prueban los cuatro testimonios manuscritos - tres de ellos de la segunda mitad del XV y uno de mediados del XVI-que conocemos y que son la base para la edición crítica del texto que estamos preparando. ${ }^{14}$

Martín Alfonso Vivaldo afirma que Pedro de la Cavallería compuso el Zelus Christi en el año $1450,{ }^{15}$ fecha que tradicionalmente se ha transmitido. Es preciso señalar, sin embargo, que este dato no aparece en el explicit de ninguno de los manuscritos que conocemos, aunque en el cuerpo mismo del texto del tratado sí constan algunas referencias al año 1450 y al 1464 como fechas de inicio y de final de dicha composición. En este sentido, se debe tener en cuenta que - como suele ser habitual en textos de este género- el autor consigna el momento en el que escribe haciendo un cómputo a partir de fechas trascendentales: ${ }^{16}$

Et reperitur quod primus Rex alienigena in ludaea fuit Herodes, quo tempore uenit Christus lesus filius Mariae Virginis. Et nullus alius ante uenit, nec post, per multa tempora usque ad Annum Millesimum, Quadringentesimum, Quinquagesimum, quem modo computamus, erit certum demonstratiue quod lesus Christus fuit et est Messias promissus lacob Patriarchae, et ista latius per omnes scribentes dicuntur, sed non respondent cauillationibus ludaei. ${ }^{17}$

El glosador, por su lado, es más explícito y afirma que el autor tardó catorce años en escribir el tratado, para lo cual se

13 De esta edición han leído la obra los diversos autores que la han citado hasta hoy.

14 Aportamos información más completa sobre la transmisión de la obra y los manuscritos, así como otras consideraciones preliminares, en el artículo Ferrero Hernández y Gómez Llauger 2013.

15 Así introduce la obra y se presenta a sí mismo como editor:

«Tractatus Zelus Christi contra iudaeos, sarracenos, et infideles. Ab illustro Doctore Petro de la Caualleria, Hispano ex ciuitate Caesaraugusta, anno 1450 compositus, nec unquam impressus.

Quem, R. admodum D. Don Martinus Alfonsus Vivaldus Hispanus, author Candelabri Aurei Ecclesiae sanctae Dei I. C. ex Sacro ac celeberrimo theologorum Bononiensi Collegio Magister et Doctor, quam maxime expurgatum, cumque exemplari studiosissime collatum, et glossis eruditissimis, eisdemque copiosissimis a se conscriptis illustratum, indice praeterea locupletissimo, et numeris marginalibus auctum, exornatumque edit». Zelus Christi 1592, portada.

Para la paginación, me refiero siempre a la edición de Vivaldo (con la indicación de recto y verso después del número de página), puesto que la edición crítica no está terminada. Considero también que su consulta es más fácil en esta edición que en cualquiera de los manuscritos, y además permite la confrontación de las glosas a las cuales hago referencia en este artículo.

16 Parrilla 1994, 758.

17 «Y se constata que el primer rey extranjero en Judea fue Herodes, en cuyo tiempo vino Cristo Jesús, el hijo de la Virgen María. Y ningún otro [Jesucristo Mesías] vino ni antes ni después, durante mucho tiempo hasta el año mil cuatrocientos cincuenta, y de este modo calculamos que tenemos razón al demostrar que Jesucristo fue y es el Mesías prometido por el Patriarca Jacob, y esto lo dicen más extensamente todos los que escriben [a propósito de ello], pero no responden a los argumentos de los judíos» Zelus Christi 1592, 8v-9r, capítulo 4.1.b «Probatio primi articuli primae partis, quod Messias fuit promissus in lege». Quisiera aclarar que solamente se ofrece la traducción de las citas latinas más extensas, que aparecen en el cuerpo del artículo (no de las que aparecen en las notas a pie de página). 
basa en las fechas que el mismo Pedro de la Cavallería menciona en diversos pasajes de la obra (1450, 1461 y 1464):

Hinc patet quo anno Auctor scripserit librum. Currebat enim annus 1550 (sic). Quo tempore nondum ars imprimendi erat inuenta, fuit enim inuenta his Regionibus anno Domini 1453, ut patet in historiis et Polidoro Virgilio. Sed nota quod autor consumpsit decimumquartum annum in componendo hoc libro, quia illum incepit anno 1450, ut hic et infra numero 58 patet. Et postea in fine, numero 970 ponit annum currentem 1461. Et denique finiuit illum anno 1464 ut patet in fine, numero $983 .{ }^{18}$

Es evidente, sin embargo, que hay un error tipográfico en la cifra de inicio, ya que debería ser 1450 . El glosador aporta aquí otras referencias temporales, en este caso la invención de la imprenta, seguramente porque ya en su prólogo decía «anno 1450 compositus, nec unquam impressus». Vivaldo cita en su glosa a Polidorio Virgilio (humanista italiano, ca. 1470-1555) y seguramente su obra De rerum inventoribus (1499) como fuente para afirmar que en esa zona - «his Regionibus», que debemos entender como Aragón o Zaragoza - la imprenta no llegó hasta 1453. Ya hacia al final del tratado, al final de la glosa a del $\S 1031$, Vivaldo da las gracias — no sabemos si con una cierta ironía - por haber necesitado apenas tres años para llevar a buen término su edición, a diferencia de Pedro de la Cavallería, que seguramente empleó catorce. ${ }^{19}$

\section{EN BUSCA DE UN MARCO DE REFERENCIA: LA DISPUTA DE TORTOSA}

Las persecuciones de 1391, a las que aludía más arriba, marcaron el inicio de un nuevo paradigma de predicación y de nuevas condiciones sociales para los sujetos pasivos de la actividad misionera. Una actividad misionera que ya no tenía como fin único la conversión de los judíos que quedaban, sino también la catequización de los conversos. ${ }^{20}$ Sin embargo, y a pesar de su dureza, esas persecuciones y sus consecuencias inmediatas no fueron tan determinantes para el devenir de las comunidades judías en Aragón como sí lo fue, en cambio, la Disputatio de Tortosa. ${ }^{21}$ En este sentido, Miguel Ángel Motis Dolader afirma con contundencia que las consecuencias de la Disputa fueron evidentes «no solo en la transformación de las estructuras sociopolíticas de las aljamas y en la extinción o declive de muchas de ellas, sino también en la eclosión de un poderoso segmento social de judeoconversos ${ }^{22}$

18 «Aquí se demuestra en qué año el autor escribió el libro. Corría, pues, el año 1550 (sic). En ese tiempo todavía no se había inventado el arte de la imprenta, ya que en estos lugares se inventó en el año del Señor 1453 , tal como se registra en las historias de Polidorio Virgilio. Pero ha de anotarse que el autor tardó catorce años en componer el libro, porque lo empezó en 1450, tal com se registra aquí y más abajo, en el número 58; y después al final, en el número 970 pone que corría el año 1461; y finalmente lo terminó en el año 1464, tal como se registra al final, en el número 983» Ibídem, 8v, glosa c $§ 53$. En cuanto a las historias de Polidorio Virgilio que se citan aquí, seguramente el autor se refiere a la obra De rerum inventoribus (1499), una historia de descubrimientos y orígenes.

19 «Nos autem, gratias agimus Deo, qui intellectum dat paruulis, quique nos misericordia sua infinita ita adiuuit ut per tres fere annos continuo litteris operam dando, nec nos, ex prefesso, aliis studiis immiscendo, in dicti authoris librum limandum, corrigendum etque glossandum huc usque peruenimus» Zelus Christi 1592, 154r.

20 Riera i Sans 1987, 116

21 Combescure y Motis Dolader 2003, XIV; Motis Dolader 2013, 16

22 Motis Dolader 2013, 16. El autor añade, a continuación, que todo ello significó «el principio del fin de la permanencia de esta minoría confesional en nuestro Reino».
Dicha controversia, auspiciada por el papa Benedicto XIII, se celebró en Tortosa del 7 de febrero de 1413 al 13 de noviembre de 1414. En ella, el también converso Jerónimo de Santa Fe (antes Yehosú 'a ha-Lorqí y, ya como cristiano converso, médico de Benedicto XIII) pretendía demostrar que los argumentos a favor del mesianismo de Jesús estaban ya contenidos en la Biblia hebrea y en el Talmud. De hecho, el papa anunció que el tema de discusión no era cuál de las dos religiones era la verdadera -en ningún caso se ponía en duda la veracidad del cristianismo-, sino, únicamente, que de acuerdo con el Talmud el Mesías ya había venido. ${ }^{23} \mathrm{Y}$, para ello, se organizó lo que para varios autores no fue tanto una disputa stricto sensu, sino más bien la escenificación de un adoctrinamiento: ${ }^{24}$ porque su fin último no era tanto debatir como, sobre todo, «instruir»" ${ }^{25}$ "adoctrinar» a los sabios judíos del reino que allí acudieron. Moisés Orfali, en un artículo reciente, afirma incluso que, dadas sus características, prefiere referirse a dicho acontecimiento como una "catequesis». ${ }^{26}$

Aunque el proyecto inicial era celebrar esta disputa en Alcañiz, patria de Jerónimo de Santa Fe, y que tuviera un carácter más local, finalmente «el papa Benedicto XIII, en noviembre de 1412, cursó una invitación a todas las aljamas de la Corona de Aragón para que enviasen sus representantes a Tortosa el 15 de enero de 1413. Las dos grandes figuras del judaísmo, Hasdai Gresgas y Bienbeniste de la Cavallería, habían muerto recientemente, para desgracia del sector hebreo». ${ }^{27}$ Sin embargo, la familia de la Cavallería estuvo ampliamente representada en la Disputa y, sobre todo, fue uno de los grandes linajes hebreos que sufrió sus consecuencias, tanto por la conversión masiva de la mayoría de sus miembros como por el asedio que en adelante algunos de ellos sintieron en su nueva condición de conversos. ${ }^{28}$

\footnotetext{
23 Krauss 1995 (2008), 172.
}

24 Se designa con los términos «disputatio, en la acepción escolástica del término; adoctrinamiento, en su vertiente religiosa, o disputacion, como la denominan los judíos». Motis Dolader 2013, 15. "Adoctrinamiento» es también el término que utiliza Asunción Blasco Martínez $(1997,261)$ : «En cuanto a lo ocurrido en Tortosa en 1413-14, he preferido el término adoctrinamiento [...] al de "disputa" tradicionalmente empleado, pues en Tortosa no hubo un intercambio de opiniones entre los asistentes, sino un intento de adoctrinar a los representantes judíos desde el principio hasta el fin».

25 Motis Dolader 2013, 19.

26 «I prefer to use the term 'Catechesis' rather than 'Disputation', since the form in which the events occurred, both in time and duration, are not characteristic of a 'Disputation'. I wish to point out that the Dispute of R. Yehiel in Paris (1240) or the one of R. Moses Ben Nachman in Barcelona (1263), occurred during a rather restricted period». Orfali 2019, 249.

27 Santoja Hernández 2012, 137. Maria Asunión Blasco también se refiere a estos hechos y a las consecuencias tan negativas que la muerte de Hasdai Gresgas y de Benvenist de la Cavallería tuvieron para la aljama de Zaragoza que, hasta aquel momento, "seguía siendo el primer centro judío de la Corona de Aragón». Insiste asimismo en la importancia de la predicación de Vicente Ferrer y del adoctrinamiento de Tortosa como catalizadores principales de la «desintegración de la judería zaragozana». Afirma, finalmente, que "estos dos hechos, en apariencia inofensivos, tendrían en el reino de Aragón una repercusión muy similar a la que los alborotos de 1391 habían tenido para el resto de la Península». Blasco Martínez 1997, 276.

28 Consecuencias que el propio papa consignó en su bula Etsi doctoris gentium. "Al finalizar las sesiones de esta "disputa", el número total de conversiones se estimaba en más de tres mil, entre ellas las de algunas familias ilustres, como la de Caballería en Zaragoza, la de Todros Benveniste o la de Todros Abencabra. Fue una conversión tan 
Sabemos, de hecho, que diversos miembros de la familia de la Cavallería se convirtieron al cristianismo durante o justo después de la Disputa, tal como leemos en la introducción que Antonio Pacios López hace a las Actas de la Disputa de Tortosa, en el apartado donde el autor resume el desarrollo de sus sesiones. Así, resulta que después de una intervención brillante de Jerónimo de Santa Fe, en respuesta a la impugnación, por parte de tres rabinos (Ferrer, Matatías y Astruch), de dos autoridades talmúdicas con las cuales Jerónimo había probado la venida del Mesías, «el 2 de febrero [de 1414], pidieron el bautismo diecisiete miembros de la familia de la Caballería, una de las más nobles entre los judíos». ${ }^{29}$

Parece, pues, que el devenir de la familia de la Cavallería y, con ella, seguramente, el del autor del Zelus Christi, están muy relacionados con las consecuencias directas de la Disputa de Tortosa. Consecuencias que se concretaron, no solo en las conversiones masivas ya mencionadas, sino también en la bula papal Etsi doctoris gentium, del 11 de mayo de 1415, que limitaba sensiblemente los derechos de los judíos y, entre otras medidas que continuaban la senda de la catequización, los obligaba a asistir a tres sermones al año. Los themas de estos sermones eran los siguientes: el primero, que tenía lugar en Adviento, debía demostrar, a partir de los profetas y del Talmud, la venida del Mesías; el segundo, en Semana Santa, versaría sobre los errores y falsedades del Talmud; finalmente, el tercer sermón, pronunciado en verano, debía exponer que Jesús predijo la destrucción del Templo y el largo exilio judío. ${ }^{30} \mathrm{~A}$ mi juicio, este hecho es relevante para la cuestión que nos ocupa porque pone de relieve la importancia de la predicación también en estas nuevas coordenadas que se definen a partir de la Disputa. Y porque el sermón ${ }^{31}$ y el uso de las Escrituras y del Talmud serán también elementos clave que Pedro de la Cavallería recoge y utiliza con habilidad para su propósito de refutación antijudía.

Ante lo expuesto hasta aquí, creo poder afirmar que la Disputa de Tortosa evidenció un claro punto de inflexión en cuanto a la estrategia de refutación antijudía en la Corona de Aragón. Porque, además de ser un claro ejemplo de adoctrinamiento y catequesis para forzar la conversión de un gran número de judíos, en ella se evidenció un giro en la estrategia de refutación del judaísmo, que se centró exclusivamente en la demostración de que el Mesías ya había venido y se dejaron de lado algunos de los temas que habitualmente también formaban parte de la polémica. Y ello se hizo, en gran parte, mediante el uso del Talmud: primero precisamente como prueba cristológica ${ }^{32}$ - hasta la sesión $62-$ y a con-

masiva, que desaparecieron aljamas en su totalidad y otras quedaron muy disminuidas». Ibídem, 137-138.

29 Pacios López 1957, 1: 74. Dice así el texto latino de las Actas (p. 557 , tomo 2, sesión 62): «Tunc divina gracia inspirante, iudei notabiliores qui essent in congregacione eorumdem, tam in sciencia, quam in genere, ut puta illi de genere militari, id est, de genere de la 'cavellaria' [E. cavaIlieria] vulgariter nuncupati, civitatis Cesarauguste, numero decem et septem personarum, in civitate Dertuse secunda die februearii, uxoribus ac domesticis eorumdem minime computatis, qui in quantitate magna fuerunt, sanctum baptisma receperunt». Véase también Combescure y Motis Dolader 2003, XVII, donde se da una relación de «personas de relieve» que asistieron a la Disputa de Tortosa en representación de su comunidad de origen». Asimismo, son relevantes para ello los artículos de Motis Dolader (2013) y de Blasco Martínez (1997 y 1999).

30 Krauss (1995) 2008, 175-176 y 190.

31 Especialmente en el prólogo, como se verá más adelante.

32 Ysraeli 2019, 171. tinuación -a partir de la sesión número 63-, en cambio, usándolo como objeto de refutación, lo cual queda también perfectamente reflejado en las obras de uno de los principales artífices de la Disputa, Jerónimo de Santa Fe. ${ }^{33}$

\section{PATRONES NARRATIVOS Y ESTRUCTURA DE LA OBRA}

Estos elementos, en fin, parecen haber condicionado también la redacción del Zelus Christi, aunque se trata de una obra compleja que no puede reducirse a un solo patrón o a una fuente claramente definida. Se encuentra, en realidad, a caballo entre el sermón y el tratado, y a caballo también entre una tradición anterior que lo determina y una cierta mirada hacia adelante que, seguramente, lo aleja un poco de las obras más duras contra los judíos. Esta mirada hacia adelante se concreta, a mi modo de ver, en el uso que Pedro de la Cavallería hace de la autoridad de san Pablo - como se verá en el siguiente apartado-, que ya era habitual en otros autores contemporáneos como Pablo de Santa María o Alonso de Cartagena. ${ }^{34}$ Una autoridad que aporta un elemento retórico nuevo al Zelus Christi respecto de otras obras con las que se lo acostumbra a relacionar. ${ }^{35}$

Es cierto que, en términos generales, el patrón narrativo y argumentativo del Zelus Christi se acerca al modelo de polémica antijudía de los siglos XIII y XIV. Y, de entre los autores que lo preceden, destaca especialmente Ramón Martí y su Pugio Fidei, tanto por las fuentes utilizadas como, principalmente, por la adscripción de ambos tratados a una estructura aparentemente tripartita que les permite polemizar, no solo contra judíos, sino también contra musulmanes y contra gentiles y filósofos.

En cuanto a su estructura externa el Zelus Christi se organiza en dos partes principales, la primera de las cuales se divide, a su vez, en tres grandes apartados: (I) contra Iudaeos, (2) contra sectam Machometicam y (3) contra idiotas. ${ }^{36}$ La segunda parte principal, dedicada a los filósofos,

33 Sobre el uso del Talmud en la refutación antijudía, me parece muy relevante lo que afirma Moisés Orfali: «Many treatises involving religious medieval polemics sought to instruct the Jews in the Christian faith. Others were intended to discredit the Talmud's teachings, since these were considered to be the main obstacle for the conversion of the Jews. The treatises written by Hieronymus de Sancta Fidei fulfilled both of these purposes. He used innumerable extracts from the Talmud in Ad convincendum perfidiam ludaeorum and in the Catechesis of Tortosa (up to session 62) in order to demonstrate that the Messiah had already come. However, in his treatise entitled De ludaicis erroribus ex Talmut and in the second part of the Catechesis of Tortosa (sessions 63-68), he turned against the Talmud, and remarked that it contained statements against the Law, against the prophets, and against the Messiah». Orfali 2019, 249.

34 En este sentido, son de lectura obligada el artículo de Ysraeli a propósito de Pablo de Santa María (Yisraeli 2019) y de Laura Giordano a propósito de Alonso de Cartagena (especialmente Giordano 2010).

35 Obras de polémica, cuyos autores la tradición ha situado en el lado más radical de la refutación antijudía, como son Jerónimo de Sant Fe o Alonso de Espina, per ejemplo.

36 «Et primo, hoc opus diuiditur in partes duas principales. In prima demonstrabitur quod fides Christi est ipsa ueritas et sic refutabitur obseruantia legis Moysi, in qua hodie ludaei insaniunt et respondebitur aliquibus quaestionibus, et dubitationibus ludaeorum, quas faciunt contra nos, et demum Secta Mahometica refutabitur et ualidis rationibus confundetur. Ex qua parte prima infertur, etiam ad idiotas, sola rationis uirtute uigentes ut nisi delirent, hanc Fidem christi sequi et illi credere oporteat per uiuam rationem. In secunda parte demonstrabitur quod nulla rationalis anima, aut philosophica seu scientia 
es sin embargo mucho más breve que la primera. Veamos a continuación un esquema de ello, a modo de sumario:

1. Prooemium Tractatus. [1r-3r]

2. Diuisio Tractatus. [3r-3v]

3. Quae sunt Sacrae Scripturae communes Iudeo, Christiano et Sarraceno. [3v-5v]

4. Probatio primae partis [4.1] contra ludaeos. [5r-129v]

4.2. Reprobatio et refutatio sectae Machometicae. [129v-138r]

4.3. Rationes laicales contra idiotas, quae docent fidem Christi ueram et necessariam esse. [138v-144r]

5. Secunda pars principalis tractatus, ubi probatura Philosophis fidem Christi ueram esse. [144r-153v]

6. Summarium, et conclusio totius Tractatus. [153v-154v]

7. Capitulum ultimum, de probanda circa homines indiuidualiter prouidentia Diuinae. [154v-156v]

Si nos fijamos en la paginación, advertidos que la estructura del tratado es muy desequilibrada, lo cual hace sospechar que esta tripartición quizá responde más a una acomodación a un patrón narrativo heredado que a un interés real de polemizar contra musulmanes y filósofos $-u$ otros gentiles-. Este desequilibrio, que ya se observa entre las tres secciones de la primera parte principal, nos lleva a pensar que el interés fundamental de Pedro de la Cavallería se centra en la refutación que se lleva a cabo en la primera parte, y, dentro de esta, en la refutación antijudía, que es la más extensa y trabajada.

Ante esta diferencia en cuanto a la dedicación a cada parte, resulta inevitable preguntarse: ¿Cuál es la razón de ese desequilibrio, sobre todo el que se da entre la refutación contra iudaeos y la refutación contra sarracenos? Por un lado, como constata Ryan Szpiech, debemos tener en cuenta que en los argumentos vertidos en la Disputa de Tortosa hay muy pocas referencias a los musulmanes, ${ }^{37}$ lo cual podría explicar, por lo menos en parte, el menor peso específico que la «Reprobatio et refutatio sectae Machometicae» tiene en el Zelus Christi. Es significativo, en cambio, que la refutación antimusulmana se inserta perfectamente en el tono y el desarrollo lógico del tratado, siguiendo su mismo patrón argumentativo, aunque en este caso los textos sagrados que el autor utiliza se reducen fundamentalmente al Corán. De hecho, se refiere a ella (la refutación antimusulmana) justo después del prólogo, en el apartado "Quae sunt Sacrae Scripturae comunes ludaeo, Christiano et Sarraceno», donde afirma los siguiente:

Hoc praesupposito, clarum est quod lex Moysi est textus approbatus ad omnes, et est certum quod Sarraceni approbant Euangelia, ut patet in Alcorano in plerique coris, siue capitulis illius liber. Signanter in dicta cora 4 quasi in medio dicit quod iesus Christus duxit Pentateucum et Euangelia, ubi est rectitudo et lux. ${ }^{38}$

Philosophiae imbuta, in hoc saeculo uiuens potest uti ratione si fide Christi contraueniat aut non obediat, quod non contingit de fide Moysi nec de secta Mahometi». Zelus Christi 1592, 3rv («Diuisio Tractatus»).

37 Szpiech 2016, 150.

38 "Teniendo esto en cuenta, está claro que la ley de Moisés es un texto aprobado por todos, y es cierto también que los Sarracenos aprueban los Evangelios, tal como vemos en muchas suras del Corán, es decir, en muchos de sus capítulos. Especialmente en la ya mencionada sura 4, aproximadamente en el medio, en la que se dice que
Además, a propósito de este párrafo, Martín Alfonso Vivaldo insiste en remarcar la proximidad que antaño existió entre cristianos y musulmanes: "Quia a principio Christiani erant et illis etiam fuit euangelium praedicatum». ${ }^{39} \mathrm{Y}$ más adelante, ya en la «Reprobatio et refutatio sectae Machometicae», Pedro de la Cavallería afirma lo siguiente:

Vide christiane lector quomodo hic insanus [sarracenus] negando ueritatem includit in uerbis suis ueritatem, tamquam insciens et ignarus. Nam dicit quod lesus filius Mariae fuit uerbum Dei quod Deus possuit in Maria. Dicit etiam quod fuit Spiritus Dei. Si enim uerbum Dei fuit, fuit filius, quia hoc uult Euangelium Sancti loannis, quod Sarracenus fatetur et concedit. Vnde quod postea negat quod Deus non habet filium, non est dictum nisi ex ignorantia filiationis Diuinae, quia ipse putat quod illa filiatio sit more humano intelligenda. ${ }^{40}$

Así pues, y teniendo en cuenta la aparente prioridad que Pedro de la Cavallería da a la refutación antijudía, parece razonable que, además de refutar a los sarracenos en sí mismos por no seguir la fe de Cristo, los usara sobre todo como ejemplo de una infidelidad menos grave que la judía, puesto que los sarracenos sí reconocen a Jesucristo, aunque - sobre todo por ignorancia- no lo consideren hijo de Dios.

Esta ordenación externa es un fiel reflejo de la estructura interna del texto, que desarrolla una argumentación perfectamente articulada, que el autor intenta que se sustente siempre en la razón y en los textos sagrados - principalmente en el Antiguo y el Nuevo Testamento, el Talmud y el Corán-. El tono y la postura de su autor son firmes, sin fisuras aparentes, aunque evita los ataques feroces y un lenguaje excesivamente beligerante, puesto que la demostración de la veracidad de la fe de Cristo debe hacerse, según él mismo afirma, mediante "ualidis rationibus». A pesar de este tono general, el autor no duda en utilizar o citar términos propios de la controversia, como «locura» (insaniam) o "cegera» (caecitas) cuando se refiere a los judíos y otros infieles, o bien "Sinagoga de Satán» (Sinagogae Satane), cuando alude solamente a los judíos; no deja de criticar, asimismo, la «tibieza» (tepiditatem) de los «malos cristianos».

Querría, en este punto, detenerme y analizar de forma más precisa los apartados que introducen la obra: el pró$\operatorname{logo}^{41}$ y los dos breves apartados que le siguen, ${ }^{42}$ donde Pedro de la Cavallería explica la organización y el fundamento argumental del tratado. Porque, a mi modo de ver,

Jesucristo trajo el Pentateuco y los Evangelios, donde se encuentra la verdad y la luz». Zelus Christi 1592, 3v.

39 Ibídem, glosa c.

40 «Fíjate, lector cristiano, como este loco [Sarraceno], por ser tan ignorante, al negar la verdad incluye la verdad en sus propias palabras. Dice que Jesús, hijo de María, fue el verbo de Dios que Dios puso en María. Dice también que fue el Espíritu de Dios. Si fue el verbo de Dios, entonces fue su hijo, ya que eso es lo que afirma el Evangelio de San Juan, el cual el Sarraceno reconoce y acepta. Así, el que después niega que Diós tenga un hijo, lo dice solo desde la ignorancia de la filiación divina, puesto que él mismo considera que aquella filiación debe entenderse según la costumbre humana» Zelus Christi 1592, 132r.

41 Ibídem 1r-3r. Lo he incluido en apéndice, en este caso con el texto latino de la edición crítica (ya publicado en Ferrero Hernández y Gómez Llauger 2013) y la traducción al castellano. En este caso, lo citaré como Zelus Christi 1450.

42 "Diuisio Tractatus» y "Quae sunt Sacrae Scripturae comunes ludaeo, Christiano et Sarraceno». Zelus Christi 1592, 3r-4r. 
son claves para entender la intención que la sustenta, así como las bases ideológicas que justifican su escritura.

En el prólogo, las palabras de Pedro son concisas y absolutamente medidas, y dibujan la imagen concreta que el autor quiere proyectar tanto de sí mismo como de su obra. Hace hincapié en algunos detalles especialmente significativos en aras de acreditar tanto los motivos profundos como su competencia para emprender la redacción del Zelus Christi. Así, en dos ocasiones pone de relieve su voluntad, ya desde pequeño y gracias a la influencia de sus padres, de acercarse a la fe de Cristo y dedicarse a su servicio, ${ }^{43}$ convencido de los errores y la ceguera de los judíos. Incide, además, en la idea que esta convicción es fruto, principalmente, de la lectura de los libros sagrados, a los cuales habría tenido acceso directo merced a su formación en las cuatro lenguas: latín, arameo, hebreo y árabe - lo cual, a pesar de haberse convertido ya en topos de este género de tratados, parece justificado a tenor de las fuentes que el autor cita y parece manejar-. Asimismo, el conocimiento de las lenguas de los infieles a los que era necesario convertir lo acerca también al ambiente de predicación, igual que las disputas que dice haber mantenido con judíos; aspecto, este último, significativo para el análisis de la obra, puesto que la acerca al patrón de las disputas medievales e incluso al de los sermones.

...a mea tenera aetate iussu fidelissimorum parentum meorum sic in quadruplici lingua fui eruditus, Latina, Caldea, Arabica et Hebraea, ut sacri canonis Bibliae studio me mancipauerim et in seruitutem Dei me redegerim, ut a tenera mea aetate, gratia Dei, desiderio desiderauerim adhaerere Christo lesu. Et, aequando scripturam Hebraicam cum Latina, nouerim caecitatem ludaicam, et, habens cum ludaeis et Sarracenis multas disputationes, noui eorum caecitatem ualidis rationibus superatam. ${ }^{44}$

Estas credenciales le otorgan, en fin, la legitimidad necesaria para justificar su método de demostración de la veracidad de la fe cristiana mediante el uso de las fuentes escritas y de la disputa intelectual.

El prólogo ofrece, además, tres elementos que toman en él especial relieve y que se pueden analizar, a mi juicio, como aspectos clave para la interpretación de la obra: (1) el celo enardecido del autor por Jesucristo, (2) el papel tan significativo que se otorga a los profetas -en especial a Elías$y$, finalmente, (3) la autoridad concedida al apóstol Pablo.

Los dos primeros aspectos aparecen ya en las primeras líneas del prólogo, que son determinantes para comprender el tono y el modo de proceder del tratado:

«Zelo zelatus sum pro domino deo exercituum, quia derelinquerunt pactum domini filii Israel: altaria tua destruxerunt et prophetas tuos occiderunt gladio», scribitur iiio Regum xixo cao. In quibus uerbis tria mihi assumo notanda: Primo zelum quem zelari me oportet pro domino Deo exercituum: ex quibus uerbis notatur causa efficiens huius operis, quia propter zelum dei est

43 En referencia al origen social de los asistentes a la Disputa y que se conviertieron al cristianismo a raíz de ella, Motis Dolader afirma que estos viri notabiles podían permitirse viajar y, además, hacerlo en compañía de su familia, "esencialmente las cónyuges y los hijos menores de edad, como lo refrendarán con posterioridad los propios vástagos al evocar su temprana conversión, inducida o sobrevenida». Motis Dolader 2013, 21.

${ }^{44}$ Zelus Christi 1450. Véase el texto y la traducción del apéndice. aggrediendum opus istud, quod de eius fide tractabit. Secundo super quo hunc zelum assumpserim, uidelicet, quia derelinquerunt pactum Domini filii Israel, in quibus uerbis notabitur causa huius operis materialis, quia de ludaeis et Sarracenis, qui legem domini male intelligunt, tractandum est. Tertio ad quem finem et quare hunc zelum assumpserim, uidelicet, quia altaria tua destruxerunt et prophetas tuos occiderunt, in quibus uerbis notabitur causa huius operis finalis, quia de Scripturis sacri canonis Bibliae diserendum est, quae pessime lacerantur et male intelliguntur per ludaeos et Sarracenos. ${ }^{45}$

El tratado empieza y se fundamenta en una cita del Antiguo Testamento, la del profeta Elías en el libro primero de los Reyes, que se presenta mediante un desarrollo totalmente sistemático, de base racional, que será imperante a lo largo del tratado. Además, resulta muy interesante que el autor utilice esa cita como inicio de la obra, ya que recuerda al modo de proceder en la definición del thema de los sermones medievales, en los que un salmo - como aquí I Reyes $19-$ determina dicho núcleo temático. ${ }^{46}$ Parece que en esta cita ya lo diga todo. De hecho, no duda en repetirla, tal como Elías hiciera en el Libro de los Reyes (I 19,10 y 14). En ella encontramos la causa motriz, la causa material y la causa final de la obra. En ella se explica el celo (la fe) y la refutación argumentada, basada en las Escrituras.

El evidente protagonismo que Pedro de la Cavallería otorga a esta cita no es, desde mi punto de vista, en absoluto casual. En primer lugar, porque de ella emerge el término clave que a Pedro de la Cavallería le interesa destacar: el zelus, esa causa motriz que, siendo él mismo un converso, debe poseer y destacar para eliminar cualquier género de duda acerca de su fervor cristiano; zelus sobre el que también escribe el glosador, con la voluntad de definir el término y dejar claro que se trata de un buen celo, un celo justo y alejado del odio, tal como el propio Pedro lo describe: «quia zelus Christi bonus me mouit». ${ }^{47}$

El segundo aspecto fundamental que reconocemos en el prólogo es la importancia de los profetas y, en entre ellos, Elías en particular. Debemos tener en cuenta que las profecías y sus portavoces, los profetas, resultan esenciales en una argumentación encaminada a demostrar la llegada del Mesías. En este contexto, pues, la elección del profeta Elías deviene fundamental, tanto por ser considerado el más grande de todos los profetas e incluso el prototipo de todos ellos, como por su carácter marcádamente mesiánico. ${ }^{48}$

45 Ibídem.

46 En este sentido, aunque a propósito del prólogo del Contra legem Sarracenorum de Riccoldo da Monte di Croce, véase Ferrero Hernández 2019, 148.

47 A menudo Vivaldo se interesa por el sentido $u$ origen de algunos términos, tal como apreciamos en esta glosa, donde comenta lo siguiente a propósito de zelus: «De hoc sancto zelo intelligitur illud Ps. 63 "zelus domus tuae comedit me". Nota quod quamuis secundum S. Tho. 2. 2. q. 38 "zelus proprie dicitur quando quis tristatur de bono alterius": multipliciter tamen et in uariis significationibus accipitur, tam in Sacra Scriptura quam in iure. Pro inuidia enim accipitur Ps. 36. Noli aemulari in malignantibus, neque zelaueris facientes iniquitatem, idest, non inuideas. textus in cap. Ecclesia 2 De election. quem citat Albe. de Ros. in Diction. ver. zelus. Item, aliquando dicitur zelus, idest, feruor dilectionis. Vt habetur in c. 2 de Regul. libro 6. Et sic uidetur intelligi Auctor 5 et 13. Iudaei repleti sunt zelo. Item, aliquin pro desiderio iustitiae, quia zelo iustitiae dent fieri executio poenae, non odio». Zelus Christi 1592, 1r.

48 «Ya antes del 200 a.C. la cultura judía sabía de dos personajes de su tradición que se distinguían por no haber muerto y, en 
Y es que, además de la referencia al ciclo de Elías en el Libro de los Reyes del Antiguo Testamento, existe una profecía de origen talmúdico conocida como «tradición de la casa de Elías», según la cual «la duración del mundo es de seis mil años: dos mil de vanidad, dos mil de ley y dos mil los del Mesías ${ }^{49}{ }^{4}$ Esta profecía fue, precisamente, la primera de las seis autoridades que Jerónimo de Santa Fe utilizó en su demostración de la venida del Mesías durante la Disputa de Tortosa. Tanta fue su relevancia, que Antonio Pacios López escribe a propósito de ella lo siguiente: «La importancia dada en la controversia de Tortosa a esta autoridad de los seis mil años es verdaderamente extraordinaria, pues ocupa ella sola, en la discusión de la venida del Mesías, más sesiones que todas las demás juntas, y aún se vuelve sobre ella más tarde en las memorias de los rabinos Ferrer, Matatías y Astruch $»{ }^{50}$ Además, según afirma Miguel Ángel Granada en su artículo "La tradición de la casa de Elías: Astronomía, cronología, historia», dicha profecía "parece haber hecho su entrada en la cultura filosófico-teológica latina con Pablo de Burgos o Pablo de Santa María [...] en su Scrutinium Scripturarum, como confirmación (frente a la pertinacia judaica en la espera del Mesías) de que éste ya había venido con Cristo en la fecha anunciada por la tradición de Elías». ${ }^{51}$

Elías, pues, sirve ya en el prólogo como autoridad para demostrar la venida del Mesías, y al mismo tiempo anuncia la importancia irrefutable que el autor concede en su tratado a los profetas: ellos ocupan gran parte del "Quintus principalis Articulus primae partis, uidelicet, quod celebrato sacrificio corporis Messiae, debebat lex noua per electos Messiae in cordibus hominum infundi, ubi ponitur Prophetarum Veteris Testamenti discursus, de iis, quae de Christo prophetata sunt», en el cual Pedro de la Cavallería da voz a todos los profetas del Antiguo Testamento.

El último de los profetes citados es Malaquías, de quien se citan las siguientes palabras:

Sequitur cap. 4. Et quod ibi dicitur: Mementote legis Moysi serui mei, et cet. Et quod sequitur: Ecce ego mittam uobis Eliam, et cet. Ista duo turbant iudaeos. Dicunt ipsi: Ecce confirmatam legem Moysi per ultimum Prophetam. Ecce secundo, quod non uenit Elias, ergo non uenit Messias? Or, audi iudae, ad hoc ultimum de Elia, et deinde respondebo ad aliud. Et debes scire quod iudaei hanc quaestionem, sine dubium mouerunt Domino nostro lesu Christo, uidelicet, quod Elias debebat prius uenire quam Mesias. Et ipse dixit eis Matt. 2 et Marci 9 et Lucae 1 quod Beatus loannes Baptista uenerat in spiritu

consecuencia, por vivir en algún lugar celestial: Elías y Henoc. El primero había sido llevado al cielo en un carro de fuego (2 Re 2,11). Del segundo, dice el Génesis que "Desapareció porque había caminado con Dios y Él lo tomó (cconsigo?)" (Gn 5,24). La figura de Elías era ya activa en la tradición. Un pasaje agregado al final del libro de Malaquías (3,23-24), de fecha imposible de precisar, decía que Elías habría de regresar a la tierra algún día para pacificar a Israel e invitar al pueblo a convertirse antes del Gran Día de Yahvé, para evitar que Dios castigara a Israel. La tarea de Elías era relativamente limitada: no tenía que establecer el reino de Israel, sino colaborar de algún modo a su salvación, sin necesidad de ser rey ni sacerdote. Sería algo diferente y superior, y su función respecto a la salvación era de tipo mesiánico». Sacchi 2004, 414.

49 Pacios López 232 (tomo 1).

50 Ibídem. Nos hemos referido a estos rabinos unas páginas más arriba, a propósito de la conversión de varios miembros de la familia De la Cavallería después de la Disputa de Tortosa.

51 Granada 2015, 325.
Eliae, quia sicut Elias debebat in fine mundi conuertere corda patrum super filios: ita fecit Beatus loannes. ${ }^{52}$

Malaquías, el último de los profetas menores, nos dice que la misión de los profetas es precisamente recordar (mementote) con insistencia las exigencias de la Alianza, recogida en la Torá, tal como hizo Elías, el más grande de todos ellos. Y aquí, con Elías, volvemos al prólogo y cerramos, en parte, el círculo.

Ligada con esta cita inicial, un poco más adelante en el prólogo mismo, Pedro de la Cavallería ofrece otra cita bíblica, precisamente del Evangelio de san Juan, para dejar clara su voluntad de rebatir los argumentos de los que afirman que la fe de Cristo se basa en artículos de difícil comprensión, razón por la cual muchos infieles rehusarían convertirse a ella: «Motus zelo Dei, uolens demonstrare totum oppositum, confirmando et demonstrando quod uerbum Christi est uerum, qui dixit "Si crederetis Moysi, crederetis forsitan et mihi", loan. 5. cap<itulo> in fine». Esta cita alude de nuevo al zelus como motor y nos habla de la continuidad de la Ley Nueva respecto de la ley mosaica; de forma secundaria, también se refiere a la mala comprensión de la ley por parte de los judíos, que no creen que Jesucristo sea el Mesías porque, en realidad, «male intelligunt» la ley de Moisés.

La cita inicial, I Reyes 19, parece hecha a medida. Además de la causa motriz, Pedro de la Cavallería encuentra allí también la materia de la obra: el abandono de la Alianza por parte de los israelitas. Ciertamente, los judíos «male inteIligunt» la antigua ley porque no reconocen la nueva y, por tanto, es como si abandonaran también la antigua alianza. De hecho, esta falta de entendimiento y abandono de la Ley es una idea muy recurrente en la polémica antijudía ${ }^{53}$ y un leitmotiv entre los conversos. Pablo de Santa María, por ejemplo, «estaba convencido del error de la doctrina que él mismo había enseñado y que el Mesías había venido ya. El error no está en la Torá sino, precisamente, en los que no la

52 «Sigue el capítulo 4. Y lo que allí se dice es: "Acordaos de la Ley de Moisés, mi siervo, etc." Y lo que sigue: "He aquí que yo os envio a[l profeta] Elías, etc." Estas dos cosas preocupan a los judíos. Y ellos dicen: "He aquí la Ley de Moisés confirmada por el último profeta. He aquí, en segundo lugar, que Elías no viene, entonces ¿no viene el Mesías?" "Ahora escucha, judío, esto último sobre Elías, y después responderé a lo otro. Y debes saber que los judíos sin duda trasladaron esta cuestión al Señor nuestro, Jeuscristo, es decir, que Elías debía venir antes que el Mesías". Y él mismo les dijo (Mateo 2, Marco 9, Lucas 1) que san Juan Baptista vendría en el espíritu de Elías, ya que, tal como Elías, en el momento del fin del mundo, debía convertir los corazones de los padres sobre los hijos: así lo hizo san Juan». Zelus Christi 1592, 89r.

53 A propósito de ello, Ryan Szpiech afirma lo siguiente: «El papel de los judíos como "remembranza" se remonta a la teoría agustiniana del papel de la infidelidad judía en la historia sagrada. Agustín afirma que los judíos són "testigos de la verdad" porque ellos mismos no creen en ella. Como explica en su tratado Contra Fausto, la autoridad de la Biblia es aún mayor por la falta de entendimiento de los judíos». Szpiech 2016, 137. Hay que tener en cuenta, sin embargo, que este posicionamento de san Agustín que aquí se recoge no es compartido por todos; y en este sentido es muy interesante el artículo de Paula Fredriksen (1995), que defiende una actitud tolerante del de Hipona respecto de los judíos; dice aquí, por ejemplo: «Augustine's vision of the Jews as a living witness to Christian truth was both original and, compared with his attitude toward pagans and non-Catholic Christians, uncharacteristically tolerant. Unlike these two other groups, contemporary Jews, Augustine argued, had a continuing positive role to play in the story of redemption. Dispersed throughout the earth since the Roman destruction of rebel Jerusalem, their hostile community witlessly preserved the original prophecies to Christ, and thereby testified to Christian truth». Fredriksen 1995, 299-300. 
siguen fielmente».54 Esto nos ayudaría a explicar, también, la expresión "derelinquerunt pactum domini», que se referiría tanto a los antiguos judíos que no reconocieron a Jesús como Mesías como, posiblemente, a aquellos contemporáneos de Pedro de la Cavallería que no interpretan bien la Ley y hacen caso, por ejemplo, del Talmud.

Así, el uso de los textos sagrados es imprescindible en una obra cuyo objetivo es la refutación de base racional y argumentativa. Porque, si los judíos y los sarracenos no entienden bien o se apartan de las Escrituras, hay que volver a ellas para demostrar la veracidad del mensaje de Cristo. Y efectivamente así lo hace Pedro de la Cavallería, que escribe un tratado, si no dirigido exclusivamente a un público erudito, ${ }^{55}$ sí con una gran carga doctrinal y en el que el autor zaragozano demuestra un manejo muy grande tanto de las Escrituras como del Talmud. Cuesta de creer, de hecho, que fuera un laico quien lo escribió. ${ }^{56}$

\section{UN «CIERTO» TONO PAULINO}

El tercer y último de los aspectos que aparecen en el prólogo y que consideramos importante para la interpretación del Zelus Christi es la autoridad que el autor concede a san Pablo. En este caso, Pedro de la Cavallería cita un pasaje de la segunda carta a los Corintios:

Aggrediar hoc opus in nomine lesu Christi, ubi demonstrabo cuicumque sano intellectui, ludaei primum et Sarraceni, et etiam Philosophi et cuicumque infideli, quod Fides Christi est ipsa ueritas, ut iuxta uerbum Apostoli «redigatur in captiuitatem omnis intellectus in obsequium Christi». 2. Ad Corinth<0s>. 10.57

Esta cita permite al autor reforzar la idea de que la evidencia de la veracidad de la fe de Cristo llevará a los infieles al convencimiento ( «redigatur in captiuitatem omnis intellectus») de la necesidad de convertirse. Se trata, pues, de utilizar los argumentos adecuados, de ser lo suficientemente convicente, para hacer cautivo el pensamiento de judíos, sarracenos y otros gentiles, y conducirlo al convencimiento de la veracidad de la fe cristiana. Sin embargo, ¿podría el uso de esta cita tener alguna otra función? A mi modo de ver, tal como he argumentado hasta aquí, todas las citas del prólogo son fundamentales para comprender la organización y la intención del tratado. Así, el uso de san Pablo también es un elemento clave que debemos analizar con atención. En este sentido, hay que considerar dos cuestiones: por un lado, el uso concreto de la referencia a 2 Cor 10 y su función en el prólogo - al mismo nivel que las otras citas-y, por otro, el alcance más amplio que podría tener el uso general de la autoridad paulina en el conjunto del tratado.

\footnotetext{
54 Sánchez Tortosa 2015, 160.

55 «... hay que tener en cuenta que el Zelus Christi de Cavallería era algo más [que] un mero tratado dirigido a un puñado de eruditos. Al contrario, parece que estaba bastante difundido al menos en Aragón, hasta el punto que los argumentos allí expuestos iban a tornarse decisivos cuando, en los años ochenta, la Inquisición lanzara una auténtica persecución contra las cabezas más visibles de este linaje». Pereda 2007, 100-101.

56 A pesar de que no tenemos ninguna prueba de que su autor no fuera el Pedro de la Cavallería Maestre Racional de Aragón, en el artículo que escribimos con Cándida Ferrero en 2013 nos atrevimos a dudar sobre este particular: cfr. Ferrero Hernández y Gómez Llauger 2013, 200.

57 Zelus Christi 1450, «Prooemium» (véase el anexo).
}

En primer lugar, pues, debemos concretar que la cita que aquí nos ocupa se encuentra en el capítulo 10,5 de la epístola, capítulo que contiene una clara defensa del Apóstol contra sus detractores. Y esto nos lleva a considerar que esta defensa propia de san Pablo en realidad podría ser, para Pedro de la Cavallería, el reflejo de la suya. ${ }^{58}$ Una voluntad - o necesidad- de defenderse - o de protegerse- que ya se deja entrever en el émfasis que el autor pone en el celo de Cristo como motor para escribir el tratado.

Hay que recordar, en este sentido, que Pedro de la Cavallería era muy posiblemente un autor converso, con una alta posición en la Corte (fue Maestre Racional de Aragón),,59 que podía ver peligrar su condición de privilegio por los problemas derivados del levantamiento popular contra los conversos que tuvo lugar en Toledo en 1449 y por los demás altercados que se sucedieron durante la segunda mitad del siglo XV tanto en Castilla como en Valencia y Aragón, a pesar de la actitud menos virulenta de principio de siglo. ${ }^{60}$ Así, los consiguientes "estatutos de limpieza de sangre» y diversas acciones contra judíos y conversos (y moriscos) pudieron ser un factor determinante para que nuestro autor, de quien solo conocemos esta obra, escribiera un tratado que le pudiera servir de escudo ante eventuales ataques por parte de sus detractores. De hecho, y a pesar de que no hay un claro consenso en ello, varios autores citan el ya célebre pasaje en el que supuestamente Pedro de la Cavallería habría reconocido, durante una celebración más o menos clandestina del sábat, que su conversión era poco más que una farsa. ${ }^{61}$

Más allá del prólogo, encontramos otras citas o referencias a san Pablo a lo largo de todo el tratado ${ }^{62}$ y, por supuesto, en las glosas de Martín Alfonso Vivaldo. De hecho, el editor sí afirma sin ambigüedades que "auctor es imitator D. Pauli»

58 Este posible uso de la autoridad paulina lo reconoce también Yosi Yisraeli en Pablo de Santa María, Scrutinium Scripturarum): "The image of Paul played an important role throughouth Pablo's theological Works as a model for a pious Jewish convert». Yisraeli 2019, 165, n. 8.

59 Algunos apuntes biográficos, analizados a la luz de la literatura previa sobre el autor, se pueden encontrar en Ferrero Hernández y Gómez Llauger (2013). Esta literatura previa se concreta, principalmente, en los siguientes artículos: Serrano y Sanz 1918, Vendrell 1943, Valdeón Baruque 2004 y Blasco Martínez 1999.

60 «Por suerte para los judíos, en 1416 se produjeron tres acontecimientos trascendentales: falleció el rey Fernando, el papa Benedicto XIII fue depuesto y fray Vicente perdió influencia en la corte y poder de convocatoria en la calle. Como el rey Alfonso no tenía ningún interés en prescindir de los ingresos que sus judíos le reportaban, hizo cuanto estuvo en su mano para que la vida judía volviera a renacer en sus estados: en 1419 consiguió que el papa Martín V derogara la bula de Benedicto XIII, y poco después su esposa, la reina doña María, revocaba gran parte de las medidas segregacionistas adoptadas por su antecesor Fernando I. Pero la ruptura ya se había producido. A raíz de los hechos que acabamos de reseñar, el sentimiento antijudío que a lo largo del siglo XIV había prendido y se había desarrollado entre los cristianos cambió de signo, y a lo largo del siglo XV se tradujo en una clara hostilidad hacia los conversos». Blasco Martínez 1997, 287. Véase también Motis Dolader 2013, 60.

61 Este episodio y otros detalles biográficos de Pedro de la Cavallería, sobre todo acerca de la posible fecha de su muerte, los registra y explica con detalle Ana Echevarría (1999, 30-33). En un ensayo posterior, Felipe Pereda insiste en recordar la condición de converso del autor de Zelus Christi y, sobre todo, que el tratado parecía ser conocido por muchos ya en 1480, cuando fue usado por los testimonios que participaron en la defensa de los miembros de la familia De la Cavallería a los que se abrió un proceso inquisitorial (Pereda 2007, 99-102).

62 Sin pretensión de exhaustividad, podemos citar Coll 2,9; Gal 3,26; Gal 2,21; Heb 7,19 y 8,6; Ef 2. 
y ya en su glosa sobre el zelus (el buen zelus), nos recuerda unas palabras del apóstol: "Sine offensione estote ludaeis et gentilibus et ecclesiae Dei» (1 Cor 10,32). ${ }^{63}$ La referencias a las epístolas paulinas serán, pues, una constante a lo largo de las glosas de Vivaldo.

En cuanto a las otras citas de san Pablo en el Zelus Christi, dos de ellas, por lo menos, nos remiten a esa voluntad unificadora que los autores proconversos reivindicaban y para la cual buscaban la autoridad paulina. Esas citas son Gálatas 3,26 y Efesios 2,16. La primera se encuentra en el capítulo «Probatio primi articulo primae partis, quod Messias fuit promissus in lege» y la segunda, en el "Quintus principalis articulus primae partis, uidelicet, quod celebrato sacrificio corporis Messiae, debebat lex noua per electos Messiae, in cordibus hominum infundi, ubi ponitur Prophetiarum ueteris Testamenti discursus de iis, quae de Christo prophetata sunt». ${ }^{64}$ Ambas, como decía, remiten a la unificación de la Iglesia en la paz, y la segunda $(E f 2,14)$ es muy significativa porque además va precedida de la célebre cita de san Juan «habrá un solo rebaño, un solo pastor» (Juan 10,16). El Apóstol dice:

Ipse est enim pax nostra qui fecit utraque unum et medium parietem maceriæ solvens inimicitiam in carne sua // legem mandatorum decretis evacuans ut duos condat in semet ipsum in unum novum hominem faciens pacem // et reconciliet ambos in uno corpore Deo per crucem interficiens inimicitiam in semet ipso. ${ }^{65}$

Pedro de la Cavallería, sin embargo, solo cita las primeras palabras del pasaje y no se alarga en absoluto en el comentario de dicha cita - ni de esta ni de las demás-, oportunidad que un autor claramente proconverso en ningún caso habría desaprovechado. Es como si Pedro remitiera al lector a todos estos referentes, que efectivamente conoce y maneja perfectamente, pero no le añade nada de pathos, sino que su tono es relativamente neutro y más bien frío.

Todo ello me lleva a afirmar que el Zelus Christi posee lo que se podría llamar un "cierto» tono paulino, cuya función he apuntado pero que todavía requiere un estudio más profundo. Este tono paulino se puede reconocer en el Zelus Christi tanto en las citas del Apóstol que Pedro de la Cavallería inserta en el texto como también, tal vez, en el tono un tanto ambiguo, relativamente matizado, que el autor usa en su refutación. Y digo "cierto» tono paulino, porque, a pesar de que todavía falta ahondar en el uso que el autor hace de san Pablo, sí es posible apuntar que no lo utilizó de manera evidente con una intención clara de defensa de la espiritualidad conversa, como sí hicieran autores contemporáneos como Alonso de Cartagena. Ciertamente, resulta inevitable pensar que esas referencias paulinas quizá podrían conducirnos en esa misma dirección, sobre todo por el peso que, a mi modo de ver, tiene esta autoridad en el prólogo. Sin embargo, los datos que hasta la fecha manejamos nos indican que el paulinismo de Pedro de Cavallería, que efectivamente existe, sería un paulinismo

63 Zelus Christi 1592, 1: «Index copiosissimus ad tractatum Zelus Christi».

64 Las encontramos, respectivamente, en las páginas $11 \mathrm{v}$ y $50 \mathrm{v}$.

65 «Porque él [Jesucristo] es nuestra paz: el que de los dos pueblos hizo uno, derribando el muro que los separaba, la enemistad, // anulando en su carne la Ley de los mandamientos con sus preceptos, para crear en sí mismo, de los dos, un solo Hombre Nuevo, haciendo la paz, // y reconciliar con Dios a ambos en un solo Cuerpo, por medio de la cruz, dando en sí mismo muerte a la Enemistad». «distinto»: no sería un paulinismo reivindicativo sino un paulinismo más bien formal, de matriz intelectual.

\section{FINAL}

El siglo XV fue sin duda un siglo convulso en cuanto a la convivencia - o coexistencia- de las diversas religiones en la Península Ibérica. Porque, aunque después de unos años terribles para los judíos, a finales del XIV podía parecer que los signos de los tiempos cambiaban gracias a iniciativas que promovían las conversiones al cristianismo mediante métodos que repudiaban la violencia física, las presiones para forzar las conversiones no cesaron. ${ }^{66}$

En este sentido, parece fuera de toda duda que la Disputa de Tortosa jugó un papel clave en este panorama: no fue solamente un elemento catalizador en las conversiones masivas de principios del siglo XV en la Corona de Aragón, sino que ofreció también el contexto y la materia para nuevas obras de polémica, principalmente antijudía, que se escribieron durante las décadas siguientes:

En la controversia de Tortosa (1413-1414), un converso dominico [Jerónimo de Santa Fe] y doctores del Talmud enfrentaron posiciones y midieron fuerzas en una disputa cuyas consecuencias marcaron, en buena medida, el destino de los reinos cristianos y del judaísmo sefardí moderno, y más genéricamente, del pensamiento filosófico europeo. En esa batalla doctrinal se juega la esencia del vínculo teológico y ontológico entre Ley Vieja y Ley Nueva, su relevancia institucional y política y los canales por los cuales es definida la herejía. ${ }^{67}$

Creo que es absolutamente verosímil que el Zelus Christi fue una de esas obras y, por tanto, además del análisis objetivo de los argumentos y de las fuentes que Pedro de la Cavallería utiliza para sustentar su refutación mediante «ualidis rationibus» - y fundamentalmente mediante las Sagradas Escrituras-, la lectura y el estudio de este tratado deben abordarse sin olvidar el contexto en el que fue redactado. Pedro de la Cavallería, sin embargo, no ofrece una polémica agria expresada con un lenguaje violento y radical, sino que apuesta por una vía de argumentación fundamentalmente intelectual y altamente erudita, que a veces se acerca, por lo menos en un estado latente - sui generis, incluso-, al paulinismo que más adelante tomará fuerza en el debate religioso peninsular. ${ }^{68}$ Un tono paulino que Martín Alfonoso Vivaldo parece poner de relieve en sus comentarios porque quizá - solo quizáeste fuera uno de los motivos que lo llevaron a editar el Zelus Christi casi un siglo y medio después de su redacción.

66 «También es preciso tener en cuenta las actuaciones llevadas a cabo por eclesiásticos, que en su afán por convertir a los judíos con medios "pacíficos" comenzaron a catequizar a las gentes sencillas obligándoles a escuchar sermones en la propia sinagoga, al tiempo que convocaban a sus dirigentes y les coaccionaban a participar en interminables discusiones teológicas, casi siempre manipuladas desde el lado cristiano: tal fue la razón de ser de la llamada "Disputa de Tortosa" de 1413-14». Blasco Martínez 1997, 260.

67 Sánchez Tortosa 2015, 150-151.

68 Sobre el estudio de la espiritualidad conversa y la hermenéutica paulina en la España del siglo XV y especialmente del XVI, son ineludibles, a parte de la obra ya clásica de Marcel Bataillon, Erasmo y España (Bataillon 1997), el libro de Steffania Pastore Il Vangelo e la spada (Pastore 2003) y los artículos de Laura Giordano (2010 y 2020). 


\section{ANEXO}

Presento a continuación el proemio ${ }^{69}$ del Zelus Christi junto con la traducción del texto latino que he elaborado:

\section{Prooemium Tractatus}

«Zelo zelatus sum pro domino deo exercituum, quia derelinquerunt pactum domini filii Israel, altaria tua destruxerunt et prophetas tuos occiderunt gladio», scribitur iiio Regum xixo cao. In quibus uerbis tria mihi assumo notanda. Primo zelum quem zelari me oportet pro domino Deo exercituum: ex quibus uerbis notatur causa efficiens huius operis, quia propter zelum dei est aggrediendum opus istud, quod de eius fide tractabit. Secundo super quo hunc zelum assumpserim, uidelicet, quia derelinquerunt pactum Domini filii Israel, in quibus uerbis notabitur causa huius operis materialis, quia de ludaeis et Sarracenis, qui legem domini male intelligunt, tractandum est. Tertio ad quem finem et quare hunc zelum assumpserim, uidelicet, quia altaria tua destruxerunt et prophetas tuos occiderunt, in quibus uerbis notabitur causa huius operis finalis, quia de Scripturis sacri canonis Bibliae diserendum est, quae pessime lacerantur et male intelliguntur per ludaeos et Sarracenos. Venio igitur ad primum. Et, quia ego Petrus de la Cavalleria, legum doctor natus in ciuitate Cesaraugustae Regni Aragonum, licet iuri ciuili et canonico operam dederim, tamen a mea tenera aetate iussu fidelissimorum parentum meorum sic in quadruplici lingua fui eruditus, Latina, Caldea, Arabica et Hebraea, ut sacri canonis Bibliae studio me mancipauerim et in seruitutem Dei me redegerim, ut a tenera mea aetate, gratia Dei, desiderio desiderauerim adhaerere Christo lesu. Et, aequando scripturam Hebraicam cum Latina, nouerim caecitatem ludaicam, et, habens cum ludaeis et Sarracenis multas disputationes, noui eorum caecitatem ualidis rationibus superatam. Et, quia in hac patria hae nationes ludaeorum et Sarracenorum frequenter pullulant, inualescunt et crescunt, suasque sectas et opiniones falsas audent asserere et clamare, continue laboraui ut sic idem lesu Christi defenderem atque dissererem, ut scirem reddere rationem omni poscenti, signanter ludaeo et Sarraceno. Et, quia multi ludaei mihi in disputationibus dicere audebant quod Fides lesu Christi non poterat persuaderi nec credi, nisi per consuetudinem illorum qui in ea nascuntur aut in ea nutriti sunt, sicut et de aliis nationibus puta ludaeorum et Sarracenorum, est notorium qui uix aut nunquam suam fidem deserere possunt, quod dicunt magis difficile et durum esse in adeptione Fidei Christianae propter eius difficiles articulos; et, ut aiebant impossibiles, adeo ut mihi in facie dicerent quod faciliores erant creditu lex Moysi et secta Sarracenorum quam Fides lesu Christi. Motus zelo Dei, uolens demonstrare totum oppositum, confirmando et demonstrando quod uerbum Christi est uerum, qui dixit «Si crederetis Moysi, crederetis forsitan et mihi», loan. 5. cap<itulo> in fine.
Prólogo

"Me consume el celo por el Señor, Dios de los ejércitos, porque los israelitas han abandonado tu alianza, han derribado tus altares y han matado a tus profetas", tal como se dice en I Reyes, 19. De estas palabras, asumo tres aspectos que deben ser remarcados. En primer lugar, el celo por el Señor, Dios de los ejércitos, que me ha de consumir: palabras de las cuales emerge la causa motriz de este tratado, puesto que es por el celo de Dios que debemos emprender la redacción de esta obra, que tratará de su fe. En segundo lugar, la razón por la cual he asumido este celo, es decir, porque los israelitas han abandonado tu alianza, palabras en las que se pone de relieve la causa material de esta obra, ya que debe tratar sobre judíos y sarracenos, los cuales no comprenden bien la ley del Señor. En tercer lugar, el fin y el motivo por los cuales he asumido este celo, a saber, porque "han derribado tus altares y han matado a tus profetas", palabras en las que se revela la causa final de esta obra, ya que se deben exponer de manera argumentada las Sagradas Escrituras, las cuales han sido mal entendidas y atacadas de la peor manera por judíos y sarracenos. Empiezo, pues, por el primer punto. Yo, Pedro de la Cavallería, doctor en leyes, nací en Zaragoza, en el reino de Aragón; $y$, aunque me he dedicado al derecho civil y canónico, sin embargo, desde muy pequeño fui instruido por orden de mis fidelísimos padres en cuatro lenguas: latín, caldeo, árabe y hebreo, lo cual me ha permitido consagrarme al estudio de la Biblia y someterme al servicio de Dios, $y$, desde una edad muy temprana, por la gracia de Dios, he deseado ardientemente adherirme a la fe de Cristo. Así, comparando la escritura hebraica con la latina, fui consciente de la ceguera judaica; $y$, en las frecuentes disputas con judíos y sarracenos, supe que su ceguera se vencía con argumentos poderosos. $Y$, como en esta tierra los judíos y los sarracenos se multiplican, prevalecen y su número continúa creciendo, y se atreven a sostener sin tapujos sus herejías y sus falsas creencias, he trabajado sin descanso para defender y explicar de forma razonada la fe de Jesucristo, para saber restituir la razón a todo aquél que lo pida, especialmente al judío y al sarraceno. Porque muchos judíos osaban decirme, durante las disputas, que la fe de Jesucristo no podía persuadir ni ser creída, si no es por la costumbre de aquellos que ya nacieron en ella o en ella fueron alimentados, tal como de otras naciones (por ejemplo los judíos y los sarracenos) es notorio que casi nunca o nunca pueden abandonar su fe, lo cual dicen que es más difícil y penoso en la adquisición de la fe cristiana por culpa de la difícil comprensión de sus artículos; y hasta tal punto los consideraban imposibles, que me llegaron a decir en la cara que resultaban más fáciles de creer la ley de Moisés y los principios de los sarracenos que la fe de Jesucristo. Movido, pues, por el celo de Dios, quiero demostrar todo lo contrario, confirmando y demostrando que la palabra de Cristo es verdadera, quien dijo «si creyerais a Moisés me creeríais a mí». ${ }^{70}$

\footnotetext{
69 Este texto está tomado, no de la edición de Vivaldo de 1592, sino de de la edición crítica del tratado en la que estoy trabajando. Una primera versión de este texto se publicó en Ferrero y Gómez Llauger 2013. La traducción se publica por primera vez aquí.

70 «Si creyerais a Moisés me creeríais a mí, porque él escribió sobre mí» (Juan, 5).
} 
Aggrediar hoc opus in nomine lesu Christi, ubi demonstrabo cuicumque sano intellectui, ludaei primum et Sarraceni, et etiam Philosophi et cuicumque infideli, quod Fides Christi est ipsa ueritas, ut iuxta uerbum Apostoli «redigatur in captiuitatem omnis intellectus in obsequium Christi». 2. Ad Corinth<os>. 10.

Igitur, solus zelus Dei, quod est primum quod dixi, contra insaniam ludaeorum et Sarracenorum ac aliorum infidelium, et contra tepiditatem malorum Christianorum, me induxit ut de fide Christi sic gloriose disseram ut dentes infidelium obtrudam efficacissimis rationibus et tam contra ludaeos quam contra Sarracenos demonstrem quod filii Israel derelinquerunt pactum Domini, idest fidem Christi, quod est secundum quod praedixi. In quo quidem secundo offertur materia operis, quae erit demonstrare quod fides Christi est uera et ipsa ueritas, et est pactum Domini uerum et fidele. Et, per consequens, ludaei, qui se dicunt filios Israel licet non sint sed sunt Sinagoga Satanae, et Sarraceni, qui in sui primordio Christiani fuerunt et sic fuerunt ueri filii Israel, omnes derelinquerunt pactum Domini, quod est fides Christi, et destruxerunt altaria Domini et prophetas occiderunt, quod est tertium. In quibus uerbis assertur finalis intentio operis, quae est quia isti infideles fundamenta nouae legis Christi destruunt altaria, idest Scripturas sacras prophetarum calumniando. Oportet ergo in parte tertia fundamenta et articulos nouae legis reformare et scripturas uiuificare in mentibus eorum, si Deus dederit. Verum, quia nolo in hoc opere uerbosos commentarios facere, quia multi me in hac materia praecesserunt et multa dixerunt, solum breuiter conabor omnia tangere compendiose et utiliter, longas disputationes omittens et uincentes rationes prosequens. Et, quia zelus Christi solum ad hoc faciendum me coegit, hunc libellum zelum Christi decreui nuncupari. Et, quia zelus Christi bonus me mouit, lectorem pium et deuotum cupio, quem hortor in Dominum, operis mentem respiciat, non imperitiam sermonis reprehendat.
Emprendo esta obra en nombre de Jesucristo, y en ella demostraré, a todo el que esté en su sano juicio $-\mathrm{y}$ pongo en primer lugar a los judíos y los sarracenos, pero también a los filósofos y otros infieles-, que la fe de Cristo es la verdad misma, para que, siguiendo la palabra del apóstol [Pablo], «se reduzca a cautiverio todo entendimiento para obediencia de Cristo». ${ }^{71}$

Así, solo el celo de Dios, que es lo primero de lo que hablé, contra la locura de los judíos, los sarracenos y los otros infieles, y contra la tibieza de los malos cristianos, me ha llevado a explicar con argumentos, gloriosamente, la fe de Cristo, con el fin de cerrar la boca de los infieles mediante razones soberanas y demostrar, tanto contra judíos como contra sarracenos, que los israelitas han abandonado la alianza del Señor, es decir, la fe de Cristo, que es lo que ya dije antes, en el segundo punto. Allí es donde se ofrece la materia de la obra, que será demostrar que la fe de Cristo es verdadera y es la verdad misma, y es la verdadera y fiel alianza del Señor. Por consiguiente, los judíos, que se llaman a sí mismos hijos de Israel, aunque no sean sino la Sinagoga de Satán, y los sarracenos, que en un principio fueron cristianos y así fueron verdaderos hijos de Israel, todos ellos han abandonado la alianza del Señor, que es la fe de Cristo, y han destruido sus altares y matado a sus profetas. En estas últimas palabras, que representan el tercer punto, se afirma la intención final de la obra, porque estos infieles han destruido los altares, los cimientos de la nueva ley de Cristo, y lo han hecho calumniando las Sagradas Escrituras de los profetas. Conviene, pues, en la tercera parte, restaurar los fundamentos y los artículos de la Nueva Ley y vivificar en sus mentes las Escrituras, si Dios lo permitiera. Sin embargo, como no quiero hacer en esta obra explicaciones abundantes y copiosas en palabras, porque son muchos los que me han precedido en esta materia y ya dijeron muchas cosas sobre ella, me dispongo a tocarlas todas solo brevemente, de forma abreviada y útil, evitando largas disertaciones y acompañado de razones convincentes. $Y$, ya que solo el celo de Cristo me ha forzado a hacerlo, he resuelto llamar a este librito El celo de Cristo. Y, ya que me ha movido el buen celo de Cristo, deseo que el lector pío y devoto, al cual exhorto hacia el Señor, tome en consideración el espíritu de la obra y no critique la impericia de mi discurso. ${ }^{72}$

\footnotetext{
71 Corintios 2,10

72 La traducción del texto latino es de la autora del artículo.
} 


\section{FUENTES}

Ad reverendi patris Claudii La Croix Societatis lesu Theologiam moralem alterius ex eadem Societate theologi supplementum, sive accessiones locupletissimae, in quibus de locorum theologicorum in morali scientia usu plurima disputantur... http://datos.bne.es/ edicion/a5716429.html https://cutt.ly/kfCp6lu

Biblia Católica. https://www.bibliacatolica.com.br/es/vulgata-latina/ epistula -ad-ephesios/2/

Vivaldo, Martín Alfonso. 1592. Tractatus zelus Christi contra iudaeos, sarracenos [et] infideles.http://books.google.com/books?id=WCe ZZVhYZTYC\&printsec=frontcover\&hl=ca\&source=gbs_ge_summar y_r\&cad $=0 \# v=$ onepage $\& q \& f=$ false

\section{BIBLIOGRAFÍA}

Bataillon, Michel. 1997. Erasmo y España: Estudios Sobre la Historia Espiritual del Siglo XVI. Madrid: Fondo de Cultura Económica.

Blasco Martínez, Asunción. 1997. «El impacto de los ataques de 1391 y el adoctrinamiento de Tortosa en la sociedad judía aragonesa». En Actas III Jornadas Hispano-portuguesas de Historia Medieval. La Península Ibérica en la Era de los Descubrimientos (1391-1492), vol. I, 278-79. Sevilla: Consejería de Cultura. Junta de Andalucía.

Blasco Martínez, Asunción. 1999. «Las expulsiones señoriales: Los Caballería y los Alazar de Zaragoza, vasallos de la Orden del Hospital». En Jews and Conversos at the Time of the Expulsion. Jerusalem: The Zalman Shazar Center for Jewish History, 155175 (en hebreo). Disponible en español en http://www.unizar.es/ cema/recursos/expulsiones.pdf

Cantera Montenegro, Enrique. 2002. «Judíos medievales. Convivencia y persecución». En Tópicos y realidades de la Edad Media (I), coord. Eloy Benito Ruano, 179-252. Madrid: Real Academia de la Historia.

Combescure Thiry, Monique y Miguel Ángel Motis Dolader. 2003. El Libro Verde de Aragón. Zaragoza: Libros Certeza.

Echevarría, Ana. 1999. The fortress of faith: the attitude towards Muslims in fifteenth century Spain. Leiden, Boston: Köln.

Ferrero Hernández, Cándida. 2019: «Lectio et disputatio en el prólogo del Contra legem Sarracenorum de Riccoldo da Monte di Croce». Mélanges de la Casa de Velázquez. 49 (1): 141-155. http://doi. org/10.4000/mcv.10489

Ferrero Hernández, Cándida y Núria Gómez Llauger. 2013. «Polémica y razón cristiana en el Zelus Christi contra ludaeos, Sarracenos et infieles de Pedro de la Cavallería». Iberia Judaica V: 195-205.

Fredriksen, Paula. 1995. «Excaecati Occulta Justitia Dei: Augustine on Jews and Judaism». Journal of Early Christian Studies 3 (3): 229-324.

Giordano, Maria Laura. 2010. «La ciudad de nuestra conciencia: los conversos y la construcción de la identidad judeocristiana (14491556)». Hispania Sacra 62 (125): 43-91. https://doi.org/10.3989/ hs.2010.v62.i125.243

Giordano, Maria Laura. 2020. «Cuando los católicos eran paulinos: Diego Pérez de Valdivia (1525-1589) y sor Hipólita de Jesús (15511624) en Barcelona (1578-1624). En Reforma católica y disidencia conversa. Diego Pérez de Valdivia y sor Hipólita de Jesús y Rocaberti en Barcelona (1578-1624), ed. Maria Laura Giordano, 33-106. Vigo - Pontevedra: Academia del Hispanismo.

Gómez Llauger, Núria. 2014. "Auctor et auctoritas en el tratado Zelus Christi contra ludaeos, Sarracenos et Infideles de Pedro de la Cavallería». En Auctor et Auctoritas in Latinis Medii Aevi Litteris.
Author and Authorship in Medieval Latin Literature. Proceedings of the VI Congress of the International Medieval Latin Committee (Benevento and Naples, November 9-13, 2010), ed. D'Ángelo Edoardo y Jan Ziolkowski, 423-433. Firenze: SISMEL - Edizioni del Galluzzo.

Granada, Miguel Ángel. 2015. "La "tradición de la casa de Elías": Astronomía, cronología, historia». Res publica. Revista de historia de las ideas políticas 8 (2): 315-338

Krauss, Samuel. (1995) 2008. The Jewish-Christian Controversy. From the earliest times to 1789, vol. 1. Tübingen: Mohr Siebeck.

Motis Dolader, Miguel Ángel. 2013. «Disputacion feyta por los judíos devant nuestro senyor papa Benedito: La conferencia de Tortosa y las aljamas judías del reino de Aragón (1413-15)». Iberia Judaica V: 15-60.

Orfali, Moisés. 2019. "Hieronymus de Sancta Fide and His Use of Sanhedrin». En The Talmud in Dispute During the High Middle Ages, ed. Alexander Fidora, Piero Capelli y Federico Dal Bo, 249265. Bellaterra: Universitat Autònoma de Barcelona.

Pacios López, Antonio 1957. La Disputa de Tortosa. Madrid: CSIC.

Parrilla, Carmen. 1994. "La literatura apologética en el siglo XV: el Declarante de judíos». En Actas del III Congreso de la Asociación Hispánica de Literatura Medieval (Salamanca, 3 al 6 de octubre de 1989), tomo II, 757-765. Salamanca: Biblioteca Española del Siglo XV. Departamento de Literatura Española e Hispanoamericana.

Pastore, Stefania. 2003. II Vangelo e la spada. L'Inquisizione di Castiglia e i suoi critici (1460-1598). Roma: Edizioni di storia e letteratura.

Pereda, Felipe. 2007. Las imágenes de la discordia: política y poética de la imagen sagrada en la España del Cuatrocientos. Madrid: Marcial Pons.

Riera i Sans, Jaume 1987. «Les llicències reials per predicar als jueus i als sarraïns (Segles XIII-XIV)». Calls 2: 114-131.

Sacchi, Paolo. 2004. Historia del Judaísmo en la época del Segundo Templo. Madrid: Trotta.

Sánchez Tortosa, José. 2015. "La Disputa de Tortosa y las semillas judeoconversas del materialismo del siglo XVII». Ingenium. Revista Electrónica de Pensamiento Moderno y Metodología En Historia de la Ideas 9: 151-171. https://doi.org/10.5209/rev_INGE.2015. v9.51546

Santoja Hernández, Pedro. 2012. «La Disputa de Tortosa. Jerónimo de Santa Fe y San Vicente Ferrer». Helmantica: Revista de filología clásica y hebrea 63 (189): 133-152.

Serrano y Sanz, Manuel. 1918. «El linaje hebraico de los Caballería según el Libro Verde de Aragón y otros documentos». Boletín de la Real Academia de la Historia LXXIII: 160-185.

Szpiech, Ryan. 2016. "Testes sunt ipsi, testes et erroris ipsius magister: El musulmán como testigo en la polémica medieval». Medievalia 19 (2): 135-156.

Valdeón Baruque, Julio. 2004. «Árbol genealógico de la descendencia de los Caballería, judíos de Zaragoza». En Isabel la Católica en la Real Academia de la Historia, dir. Luis Suárez Fernández y Carmen Manso Porto, 145-148. Madrid: Real Academia de la Historia.

Vendrell, Francesca. 1943. "Aportaciones documentales para el estudio de la familia Caballería». Sefarad 1: 115-154.

Yisraeli, Yosi. 2019. «From Christian Polemic to a Jewish-Converso Dialogue. Jewish Skepticism and Rabbininc-Christian Traditions in the Scrutinium Scripturarum». En Interreligious Encounters in Polemics between Christians, Jews, and Muslims in Iberia and Beyond, ed. Mercedes García-Arenal, Gerard A. Wiegers y Ryan Szpiech, 161-196. Leiden-Boston: Brill. 